\title{
María Teresa de Landa. Una Miss que no vio el universo
}

\author{
Paulina Pezzat Sánchez (10) https://orcid.org/0000-0001-9029-2067 \\ Doctorado en Historia \\ CIESAS-Peninsular, México \\ paulinapezzat@gmail.com
}

Rebeca Monroy Nasr, María Teresa de Landa. Una Miss que no vio el universo, México, Secretaría de Cultura/Instituto Nacional de Antropología e Historia, 2018.

En respuesta a la historia de los grandes personajes, durante el siglo XX, surgieron estudios sobre el hombre común, ya sea desde un nivel micro estudiando al individuo, o a un nivel macro como miembro de una colectividad. En este contexto, la biografía considerada uno de los géneros tradicionales de la historia, durante décadas fue menospreciada por un sector progresista del gremio histórico por su estrecha relación con la historia política al retratar trayectorias de hombres en el poder. Sin embargo, estudios más recientes han demostrado las posibilidades y la complejidad del análisis que requieren las historias de vida. El libro de la fotohistoriadora Rebeca Monroy Nasr María Teresa de Landa. Una Miss que no vio el universo es un recorrido por el ascenso, caída y redención de una mujer representante de una sociedad capitalina, contradictoria como muchas, que por un lado emitía un mensaje al mundo de modernidad en el que la mujer de clase media y alta ocupaban un papel protagónico en la economía y en la cultura, mientras que por otro, juzgaba duramente si no cumplía ciertos estándares o se mostraba con demasiada autonomía.

Considero que el término biografía no define propiamente el presente libro, pues no abarca toda la vida de la protagonista, desde su nacimiento. Por ello, me referiré más bien a 
una trayectoria de vida. El relato se construye a partir de dos acontecimientos claves que marcaron la vida de María Teresa de Landa. El primero, su triunfo como representante de México en un certamen de belleza en Galveston, Texas en 1928. Y el segundo, el asesinato por su propia mano, del que creía que era su esposo, tan solo un año después de haber sido coronada "Miss México".

Si bien el caso de María Teresa de Landa es atípico, también es cierto que forma parte de un conjunto de mujeres destacadas en diversos ámbitos, representantes de la mujer moderna mexicana que buscaban abrirse camino en un mundo dominado por hombres. La autora hace constantes referencias a sus contemporáneas María Antonieta Rivas Mercado, Carmen Mondragón, Tina Modotti como exponentes de mujeres apasionadas cuya necesidad de expresarse y encontrar un lugar en la sociedad, entraba en conflicto con el heteropatriarcado posrevolucionario dominante en la época. Paralelamente, mientras un sector femenino privilegiado luchaba por alcanzar espacios destacados en diferentes ámbitos, un sector menos afortunado ocupaba páginas de la sección de nota roja de los medios de la época. En este contexto, todos estos elementos confluyen en el caso de María Teresa de Landa, a partir del cual se pretende interpretar un periodo y una sociedad que juzga a una mujer por convertirse en victimaria de un hombre, en un país que estaba saliendo de un conflicto armado.

El libro se compone de once capítulos en los que se desarrolla la trayectoria de vida de María Teresa de Landa desde que entra al concurso para elegir a Miss México, pasando por el momento fatídico del asesinato del general Moisés Vidal, seguido del juicio que atrajo la atención de la sociedad capitalina. A diferencia de otras obras que han abordado el caso, Monroy Nasr alargó su investigación para dar a conocer la vida después de aquel episodio hasta su fallecimiento en 1992. 
En el primer capítulo “Un ramillete en flor”, la autora expone el contexto sociopolítico en el que se desarrolló el concurso de belleza organizado por el semanario del periódico Excélsior. En 1928, el país se encontraba en un proceso de pacificación después de años de enfrentamientos armados, por lo que un evento que enalteciera la belleza femenina mexicana generó expectativas entre los lectores de "Jueves de Excélsior" que esperaban noticias que hicieran olvidar la violencia en la que estaba inmersa el país. Diversos medios impresos difundían una imagen de la mujer moderna cosmopolita, cada vez más atrevida y arriesgada a mostrar su cuerpo y a abrirse caminos profesionales en campos tradicionalmente reservados para el género masculino. Lo cierto es que durante la Revolución mexicana, se abrieron espacios que fueron ocupados por la mujer, ante el déficit de mano de obra masculina. Esto generó una idealización colectiva de las posibilidades que la mujer mexicana podía alcanzar. Sin embargo, en la cotidianeidad se le continuaba juzgando por su forma de vestir, actuar y expresarse.

En el siguiente capítulo "Entre fotógrafos y periodistas te veas...", se realiza la presentación de las concursantes que compitieron junto con María Teresa de Landa. Me parece acertada la decisión de la autora de transcribir textualmente las entrevistas de las concursantes como propuesta metodológica. Por un lado, obliga al lector a ser partícipe de la construcción del relato y por otro, se les da voz a estas mujeres casi cien años después. Llegado a este punto, sobra decir que las fuentes hemerográficas son elementales para la investigación, pero no sólo es la información textual ahí impresa la que aporta la principal materia prima, sino la constante interacción con las imágenes fotográficas.

Una vez presentadas todas las concursantes, en el tercer capítulo "Una Miss que no vio el Universo” vemos el ascenso a la fama de María Teresa de Landa y el desarrollo del concurso 
como tal. Es interesante el análisis que hace Rebeca Monroy sobre el cuerpo de la mujer a partir de las fotografías, no sólo aquellas publicadas por Excélsior, sino las que aún permanecen resguardadas en el Archivo General de la Nación, tomadas por los fotorreporteros que capturaron los eventos del concurso entre quienes se encontró viejos conocidos que documentaron la Decena Trágica, pero después se dedicaron a fotografiar eventos sociales. Si bien María Teresa no ganó el concurso en Galveston, su futuro pintaba prometedor. Sin embargo, María Teresa ya tenía decidido su destino.

Desafortunadamente, después del ascenso, vino la caída, pero antes de llegar al episodio trágico, la autora dedica el capítulo “Quién eres en verdad, Moisés Vidal?” para develar la verdadera identidad del hombre que llevó a la perdición a María Teresa. Para ello, realizó una impresionante búsqueda para reconstruir el rompecabezas que representaba la identidad del militar, cuya lectura resulta intrigante ante el misterio alrededor del personaje, pero indispensable para comprender íntegramente el desarrollo de la relación que tuvo con la protagonista y su trágica culminación. Moisés Vidal y María Teresa simbolizaban el contraste de la sociedad mexicana. Él, un ex combatiente de la revolución que cargaba con un pasado violento, lleno de traiciones. Ella, en cambio, era la mujer moderna de clase media de la Ciudad de México, inteligente y educada.

En el quinto capítulo "Por propia mano: la vida misma”, entramos al clímax del libro, el momento esperado en el que la vida de María Teresa de Landa da un giro de 180 grados. Llama la atención el nivel de detalle del relato, posible en buena medida al acompañamiento de Excélsior desde que se dio a conocer la noticia y a la información resguardada en el Fondo Cárceles del Archivo Histórico de la Ciudad de México. Debido a la cercanía entre la acusada de "uxoricidio" y dicho periódico, el medio tuvo un acceso privilegiado que no tuvieron otros 
diarios. Aunque en esta ocasión, ya no aparecería en "Jueves de Excélsior”, sino en la sección de nota roja. A partir de este momento, el caso se convirtió en una ventana a la historia del sistema judicial mexicano, no sólo por el interés que despertó entre la opinión pública sino porque se trató del último juicio con jurado popular.

Debido a la importancia del juicio y a la cantidad de información que vale la pena dar a conocer, la autora dedica tres capítulos a abordar este episodio. Una vez develados los sucesos de la mañana trágica del domingo 25 de agosto de 1929, podría pensarse que el momento de mayor tensión del libro quedó plasmado en el capítulo anterior. Lo cierto es que desde el sexto capítulo "Desde el imperio de las sombras", y el séptimo "La vida caprichosa" es difícil despegar lo ojos del papel, así como seguramente les sucedió a los cientos de lectores, radioescuchas y espectadores que siguieron atentos el juicio de "Miss México" por reivindicar su honor y conservar su libertad.

La triangulación de fuentes hemerográficas, judiciales y fotográficas posibilitó reconstruir con bastante fidelidad el juicio completo. Nuevamente, la autora consideró que valía la pena realizar transcripciones textuales de fragmentos del juicio para que el lector tenga una lectura partícipe, pero también para poner a disposición este tipo de fuentes para aquellos interesados en el tema. Por otra parte, la crónica visual realizada por Agustín Casasola es por sí sola una fuente riquísima de estudio, pero el diálogo paralelo con otras fuentes transporta al lector a esa época.

En "La vida caprichosa" continua el juicio, pero dedicado mayoritariamente a la defensa. En esta parte, varios testigos fueron llamados a declarar como los padres de María Teresa de Landa, hasta que finalmente llegó el turno de "Miss México”. Un aspecto interesante de los juicios con jurado popular, era el derecho de réplica de la acusada para responder e 
incluso cuestionar a los testigos, momentos en los que nuevamente ponía en evidencia su agilidad y astucia.

Para cerrar el relato del juicio, el capítulo "Identidades perdidas: la honra encontrada” presenta el último día del proceso legal en el que se decidiría el destino de María Teresa. Durante todo el proceso judicial es posible percibir la fuerte carga moral e ideológica, a partir de la cual se pretendió juzgar a la acusada e inclinar la opinión del jurado hacia un lado u otro. La habilidad y prestigio de su abogado José María Lozano, quien concluyó su vida profesional con este juicio, y la destreza mental de María Teresa, así como un caso débilmente construido por parte de la fiscalía, fueron elementos a favor de "Miss México".

Finalmente, para concluir la trayectoria de vida, en "La resiliencia de María Teresa” se investiga lo que fue de nuestra protagonista, una vez concluido el juicio hasta el resto de su vida. Una tarea difícil pues cuando dejó de ser figura pública, se requirió de una búsqueda exhaustiva de los rastros dejados por María Teresa.

No obstante, las capacidades y habilidades desarrolladas por María Teresa, me parece que su pertenencia a un sector privilegiado de la sociedad mexicana fue un factor clave que le permitió educarse hasta estudios profesionales. Precisamente esa base económico-social le otorgó cierta ventaja durante y después del escándalo, lo que posibilitó que pudiera retomar una vida "normal" en la medida de lo posible. En cambio, otras mujeres en circunstancias menos favorables no contaron con las mismas oportunidades de salir avante. Considero que era necesario evidenciar las condiciones en las que le fue posible manejar su contexto con los elementos a su disposición, algo en lo que la autora no profundiza.

Lejos de ser un relato lineal y homogéneo, en este libro queda evidenciado que las trayectorias de vida son una ventana a diversos mundos, épocas y vidas. La complejidad del Secuencia. E-ISSN 2395-8464 
individuo y de su estudio histórico implica abordar simultáneamente las diferentes dimensiones que convergen en un mismo ser en un tiempo y lugar determinado. Precisamente, uno de los tantos aciertos de este libro es cómo la autora logra conjugar los efectos de los procesos sociopolíticos a nivel nacional en un individuo que fue llevado al límite y cuya única salida que vio posible fue acabar con su vida o la del otro. El análisis del acontecimiento a un nivel micro permite visualizar la agencia del individuo, sin perder de vista los procesos estructurales que aparecen tangencialmente, pero están presentes constantemente. En este caso, se manifiesta en la toma de decisiones, a veces instantáneas cuyos efectos permanecen latentes el resto de su existencia como le sucedió a María Teresa de Landa. 